\title{
THE DIODRAST CLEARANCE AND RENAL BLOOD FLOW IN TOXEMIAS OF PREGNANCY
}

\author{
By LEON C. CHESLEy, EMMET J. CONNELL, ELIZABETH R. CHESLEY, \\ J. D. KATZ, AND C. STEDMAN GLISSEN
}

(From the Departments of Biochemistry and Urology, Margaret Hague Maternity Hospital, Jersey City)

(Received for publication September 6, 1939)

Renal ischemia, produced by artificial constriction of the renal arteries, results in a permanent hypertension, the severity of which roughly parallels the degree of ischemia. (For reviews see Goldblatt (1) and Blalock and Levy (2)).

Smith, Goldring and Chasis (3) have shown that at low plasma concentrations diodrast has a renal extraction ratio of nearly 100 per cent and that, therefore, the plasma clearance of diodrast gives the plasma flow through the kidney. In patients having essential hypertension, Smith, Goldring, Chasis and Ranges (4) report that they always found renal ischemia, as shown by the diodrast clearance.

Toxemia of pregnancy seems to bear some definite relation to essential hypertension; about half of post-toxemic patients will sooner or later show persistently elevated blood pressure. Corwin and Herrick (5) have concluded that "subacute hypertensive toxemia of pregnancy is the response of the woman with latent or declared cardiovascular disease to the strain of pregnancy." Dill and Erickson (6) have produced an eclampsia-like syndrome in dogs and rabbits by constriction of the renal arteries in pregnant animals.

In view of the foregoing considerations, it would seem to be of fundamental importance to determine the diodrast clearance (and effective renal blood flow) in toxemia of human pregnancy.

\section{MATERIAL AND METHODS}

Patients were selected in whom the differential diagnosis could be made, with some confidence, between preeclampsia, nephritis, and chronic hypertension complicated by pregnancy. By pre-eclampsia (and eclampsia) we mean an acute toxemia occurring late in pregnancy. It is characterized by a rapid and excessive gain in weight, hypertension, proteinuria, and edema usually appearing in the order mentioned (and with or without convulsions). All these signs disappear rapidly following delivery (but not always permanently). Renal function tests, such as the urea clearance, give normal results.
Nearly all patients studied in this group were primigravidae. Our chronic hypertensives were all patients who have been observed in more than one pregnancy, and followed between pregnancies. In most of these the urea clearance was normal. Chronic Bright's disease had either been so diagnosed before pregnancy, or early in pregnancy. The criteria were: hypertension, proteinuria, edema, hematuria, diminished renal function as shown by urea clearance, specific gravity, and phenolsulphonphthalein excretion. Hypoproteinemia and hypercholesterolemia were also present in our cases.

Twelve normal pregnant and 9 normal non-pregnant subjects were used as a control series. The first 17 of these have been reported elsewhere (Chesley and Chesley (7)).

Because of the possibility of stasis of urine in dilated ureters, many of the pregnant and immediately postpartum patients were cystoscoped and ureteral catheters were inserted. A special catheter with 5 or 6 openings was placed in the bladder. From here on the procedure described by Smith, Goldring and Chasis (3) was followed. A continuous infusion of 10 per cent dextrose containing $1 \mathrm{ml}$. of 35 per cent diodrast per $100 \mathrm{ml}$. was given at the rate of $10 \mathrm{ml}$. per minute for 10 minutes; the rate of infusion was then cut down to $4 \mathrm{ml}$. per minute. About half an hour after the beginning of the infusion the bladder was washed out with saline, and the urine collection period begun. At this time the first blood specimen was taken (oxalated). Three urine collections were made, each over a period of about 20 minutes. The bladder was washed out twice each time to catch any urine which might have drained down the ureters. The washings were combined with the urine for analysis. At the end of the test the ureteral catheters were slowly pulled out with suction to get any urine that was possibly stagnating in the ureters. The second blood sample was taken midway in the test, and the third was obtained at the end. The following day (usually) the procedure was repeated without ureteral catheterization. These bladder urine collections were made over a period of about 45 minutes, and the preliminary period of infusion was prolonged. (See Discussion below).

Diodrast was analyzed as iodine, using a modification of Kendall's method as adapted by Smith, Goldring and Chasis (3). The use of glass beads was omitted, and the samples of plasma and diluted urine were dried over night at 85 to $95^{\circ} \mathrm{C}$. After fusion, the cooled melt was dissolved by adding water to the crucible and boiling carefully on a hot plate. The solution was poured di- 
rectly into the analysis flask, and the crucible then rinsed six times with cold water brought to boil in the crucible. The final titration was made with $0.001 \mathrm{~N}$ sodium thiosulphate. All reagents were freed of iodine by the methods described by McCullagh (8). Blank analyses were always negative. Frequent analyses of known solutions of both hippuran and potassium biiodate in urine and plasma gave results close to theoretical. All determinations were done in duplicate.

The plasma clearance of endogenous creatinine was simultaneously determined by the methods of Folin (9). When the urine volume was in excess of $2 \mathrm{ml}$. per minute, the maximal urea clearance was measured by the manometric procedures of Van Slyke (9). toxemic patients were antepartum and at the height of their toxemia.

In Table I are shown the plasma clearances of diodrast, endogenous "creatinine" and urea, the hematocrits, and the calculated renal blood flows, "filtration fractions" and urea extraction ratios. The " filtration fraction" was calculated by dividing the clearance of apparent creatinine by the diodrast clearance (renal plasma flow). We do not regard the endogenous creatinine clearance as a measure of glomerular filtration, though we had thought that it might give an approximation to

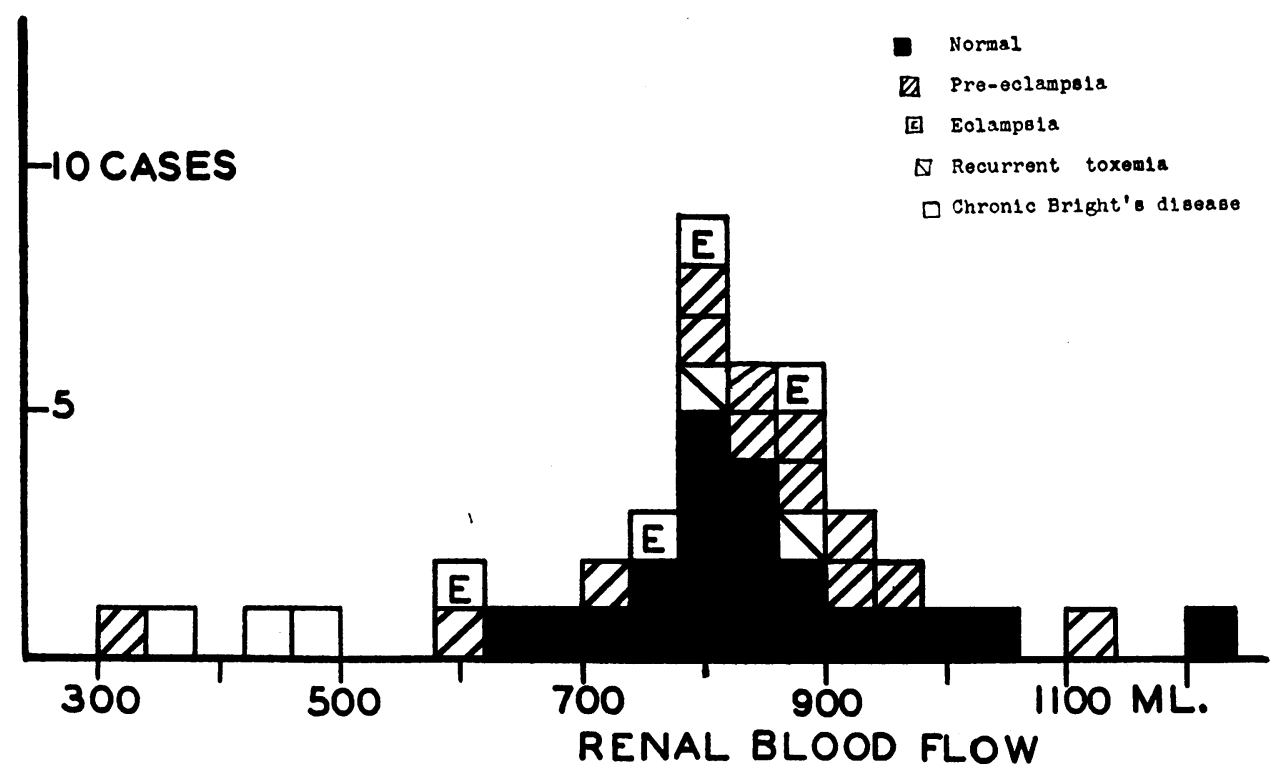

Fig. 1. Frequency Distributions of Renal Blood Flows in Normal Subjects and in Pre-eclampsia, Eclampsia, Recurrent Toxemia, and Chronic Bright's Disease Complicating Pregnancy

All observations on eclamptics were made after delivery; on the first, the third, and two on the eighth postpartum days.

For the determination of the plasma fraction, $1 \mathrm{ml}$. of well mixed blood was placed in a vaccine tube (designed by E. M. MacKay (9) ) and centrifuged at 2500 r.p.m. for an hour. The volumes of cells and plasma were then read directly.

The effective renal blood flow was calculated by dividing the plasma clearance of diodrast by the plasma fraction. Hereafter, this figure will be called simply " renal blood flow." All clearances are corrected to the ideal body surface area of 1.73 sq. $\mathrm{m}$.

\section{RESULTS}

The renal blood flows for all subjects are shown in Figure 1. Unless specifically noted, all the filtration rate. It would be hard to say what it does represent, since it seems to bear no constant relation to the urea clearance as it should if it were related simply to the glomerular filtration. Evidently all of the apparent creatinine of the plasma either is not filtered, or does not escape tubular reabsorption. Furthermore, the proportion so behaving varies from subject to subject. Our "filtration fraction" is therefore worthless.

The urea extraction ratio was computed by dividing the plasma clearance of urea (assumed to be nearly the same as the whole blood clearance) by the calculated renal blood flow. The extrac- 
TABLE I

\section{Toxemic series of 24 patients}

All data corrected to body surface area of $1.73 \mathrm{sq} . \mathrm{m}$. Ureteral catheter specimens used in many cases. Blood pressure measurements made at time of test.

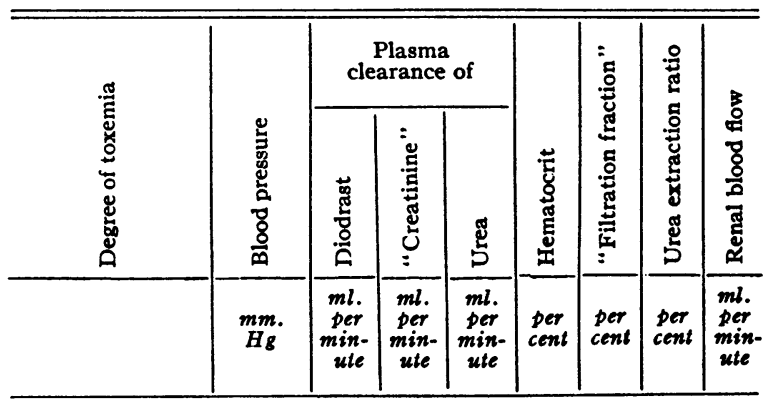

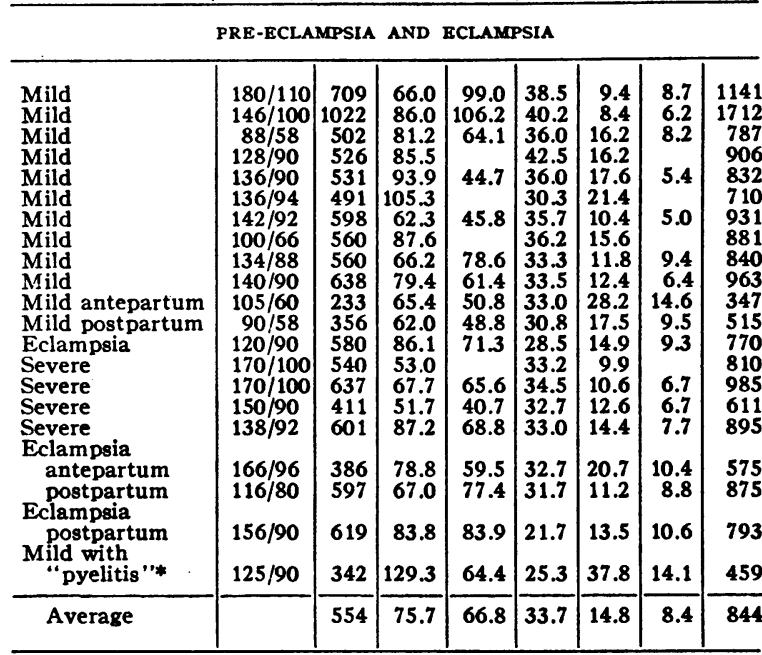

RECURRENT TOXEMIA

\begin{tabular}{r|r|r|r|r|r|r|r|r}
\hline & $200 / 130$ & 564 & 103.8 & 160.0 & 35.7 & 18.4 & 18.2 & 880 \\
& $138 / 80$ & 583 & 57.5 & 56.2 & 28.0 & 9.9 & 6.9 & 809 \\
\hline
\end{tabular}

" Not averaged because of "pyelitis."

tion ratio thus obtained averages 8.7 per cent for all subjects. This agrees with the average of 8.7 per cent calculated from the data of Landis, Elsom, Bott and Shiels (10), and accords well with the data obtained by simultaneous analyses of systemic arterial and of renal venous bloods in dogs and rabbits (for review see Chesley and Chesley (7)).
The renal blood flow in patients with preeclampsia and eclampsia covers a wide range but is usually normal. In 1 case of mild pre-eclampsia the extraordinarily high blood flow of $1712 \mathrm{ml}$. per minute was found. In another mild preeclamptic the flow was $347 \mathrm{ml}$. per minute; when the test was repeated 11 days later and after delivery, the blood flow was $515 \mathrm{ml}$. per minute. Clinically, this patient had a typically pre-eclamptic toxemia, presaged in the eighth month by a rapid gain in weight, followed by the appearance of hypertension and then of proteinuria and other signs and symptoms of pre-eclampsia. In one of the 4 eclamptics, the diodrast clearance was done between convulsions; her renal blood flow at that time was $575 \mathrm{ml}$. per minute. When checked 8 days after delivery, the blood flow was $870 \mathrm{ml}$. per minute. Perhaps the somewhat diminished level found at the time of the convulsions can be attributed to renal vascular spasm or possibly to the sedative (allonal). One patient is not included in the averages, though the data are given in Table $I$. This patient was found to have a "pyelitis" which quite possibly could affect the clearances, since "pyelitis" usually involves at least some of the renal parenchyma.

For the whole group of eclamptic and preeclamptic patients, the mean renal blood flow is very close to that of the normal group at 844 ml. per minute, with a standard deviation of $253 \pm 27 \mathrm{ml}$. The standard error of the mean is $5 \overline{6.6} \mathrm{ml}$. All of the clearances studied were nearly the same as in the normal control group which averaged $850 \mathrm{ml}$., with a standard deviation of $126+13.1 \mathrm{ml}$. The standard error of the mean for the normal group of 21 subjects was $27.6 \mathrm{ml}$. The "filtration fraction" and urea extraction ratio averaged very slightly higher for the toxemia patients than for the normals.

Two multiparous patients were studied in whom repeated toxemia of pregnancy had occurred and in whom blood pressures were always found to be elevated between pregnancies. Both were again toxemic and near term. The renal blood flows were normal -880 and $809 \mathrm{ml}$. per minute (Table I).

Four patients with chronic Bright's disease were observed. At least 2 of these have nephrosclerosis. The results shown in Table II indicate 
a diminished renal blood flow, averaging about half that of the control or pre-eclamptic subjects. The "filtration fraction" is increased, as observed by Smith, Goldring, Chasis and Ranges (4) in their cases of essential hypertension. Curiously enough, the urea extraction ratio is slightly lower than the average; or in other words, the urea clearance runs nearly parallel with the diodrast clearance. This disparate behavior of the clearances of endogenous "creatinine" and urea (in only 3 cases) suggests that perhaps there is an increased tubular permeability allowing backdiffusion of urea to the blood. An impairment in tubular function (secretory) has been demonstrated in essential hypertension by Smith et al. (4). Landis, Elsom, Bott and Shiels (10) found that the urea clearance paralleled fairly well the hippuran clearance (as did the creatinine clearance).

\section{TABLE II}

Comparison of diodrast clearances with urine specimens obtained by ureteral catheters and by bladder catheter

\begin{tabular}{c|c|c|c|c|c|c|c|c|c|c}
\hline \hline Patient & 1 & 2 & 3 & 4 & 5 & 6 & 7 & 8 & 9 & $\begin{array}{c}\text { Aver- } \\
\text { ages }\end{array}$ \\
\hline $\begin{array}{c}\text { Ureteral cath- } \\
\text { eter specimens }\end{array}$ & 505 & 598 & 610 & 416 & 374 & 588 & 756 & 632 & 492 & 552 \\
$\begin{array}{c}\text { Bladder cath- } \\
\text { eter specimens }\end{array}$ & 543 & 702 & 518 & 393 & 568 & 532 & 588 & 555 & 607 & 556 \\
\hline
\end{tabular}

* Patient received 2 capsules of nembutal at time of catheterization.

To summarize, the renal blood flow is not affected (usually) in pre-eclampsia and eclampsia. In such toxemias, two diminished and one markedly increased renal flow have been observed in 20 cases. In chronic Bright's disease complicated by pregnancy, there is a marked diminution in the renal blood flow. This, in our cases, was accompanied by a decrease in the urea clearance.

There was no significant effect upon the blood pressure exerted by the small amounts of diodrast given. The blood pressure increased slightly in about as many cases as it fell. In only 1 case - the eclamptic whose diodrast clearance was done between convulsions-was the pressure change at all marked. In this case the blood pressure at the beginning of the test was 146/90, and at the end it was $100 / 70$. (Wide fluctuations in blood pressure are characteristic of eclampsia and preeclampsia.)

\section{DISCUSSION}

Urine collections. The quantitative collection of urine in the pregnant and puerperal woman is difficult because of bladder atony and ureteral dilatation, with consequent stagnation of urine. Furthermore, the bladder is often displaced downward and pockets are formed which are hard to drain by catheter. In the present study an effort has been made to make complete collections of bladder urine by using a multi-opening catheter. At each collection period the bladder was washed out twice with $20 \mathrm{ml}$. of saline as recommended by Smith. External suprapubic pressure often aided in getting back the instilled saline.

Ureteral dilatation, found in about 85 per cent of pregnant women (Stander (11)), may occasionally be of such marked degree as to hold back from the bladder an hour's output of urine. Bladder urine collections cannot give reliable clearance calculations unless the blood level of the substance under study is essentially constant, and unless the degree of diuresis is nearly constant or high. Even then an occasional strong peristaltic wave in the ureter might sweep accumulated urine into the bladder.

In the tests in which bladder urines were used, an effort was made to minimize the vitiating factors mentioned. In all cases the blood level of diodrast was kept very nearly constant. (The greatest variation in any case, excepting the few in whom low clearances were encountered, and one variation of 27 per cent, was 13 per cent; the average maximal variation from lowest to highest observed blood levels was 9.2 per cent. Almost invariably the blood level of diodrast progressively but slowly increased). The period of infusion before the beginning of the urine collection period was at least 40 minutes. Thus diodrast-containing urine would not be diluted by stagnating diodrast-free urine in the ureters. Moderate to high degrees of diuresis were maintained; sodium sulphate was not used. Urine collection periods lasted 45 minutes; three urines were collected.

As stated in the description of methods, ureteral catheterization was done in many of the pregnant patients. Since the catheters are small, some urine might pass down the ureters outside of the catheters. Such urine has been collected as described above. We feel that in these catheterized 
patients the urine collections have been quantitative. However, another possible complication arises. Ureteral reflexes set up by the catheterization have been known to cause anuria, probably by renal circulatory disturbance. (No evidence of such disturbance has been observed in our present series). If so marked an effect as anuria can result from ureteral catheterization, it might be that some lesser renal circulatory disturbance would often occur.

As a double check, first upon the reliability of bladder urine collections and second upon the possibility of ureteral reflex inhibition of renal blood flow, the diodrast clearance was done twice on each of many of the patients. Usually the first clearance was done with ureteral catheter collections; the following day (usually), or within a week, the clearance was repeated with bladder collections. As the data in Table II show, the clearances may be done either way. In half the cases the bladder urines gave the higher clearances, and in half the ureteral urine gave higher results. The total averages for the two groups are similar. The advantage of the ureteral catheterization lies in the satisfying agreement between successive clearances. The discomfort to a pregnant patient near term, however, outweighs this advantage.

Hypertensive complications of pregnancy. Despite the considerations outlined in the introduction, which seemed to promise so well for renal ischemia as a cause (or even the principal cause) of toxemia of pregnancy, the renal blood flow seems to be characteristically normal in preeclampsia, eclampsia and "recurrent toxemia." Moreover, this finding pushes back another step the defenders of the old hypothesis that renal insufficiency underlies toxemia of pregnancy. After a century of slow, stubborn retreat from the position that eclampsia was uremic in nature, the argument of this school must now be based upon how much the renal blood flow could be if all the blood vessels of the kidney were maximally dilated.

Many of the patients whom we have diagnosed as " mild pre-eclampsia" would be called "low reserve kidney" by obstetricians using that classification. If one had previously doubted that a renal deficiency underlay the mild toxemia called
" low reserve kidney," his doubts must now be increased by the demonstration of a normal renal blood flow in such cases.

Since the renal blood flow characteristically seems to be normal in pre-eclampsia and eclampsia, one might expect renal function tests to give normal results when extra-renal factors are taken into account. Such is the case (Chesley (12, 13)).

\section{SUMMARY AND CONCLUSIONS}

In eclampsia, pre-eclampsia and recurrent toxemia of pregnancy, the renal blood flow, as measured by the diodrast clearance, seems to be characteristically normal. There is a wider range above and below average than was found in the normal subjects.

In the few cases of chronic nephritis complicating pregnancy studied, the calculated renal blood flow is considerably below the levels found in normal subjects.

The urea extraction ratio averages 8.7 per cent, as calculated from the plasma clearance of urea divided by the renal blood flow.

We wish to acknowledge our indebtedness to Drs. S. A. Cosgrove, J. F. Norton, and E. G. Waters for their permission to use patients from their services, and for reading the typescript. Dr. $P$. O. Hall has allowed us to study several of his private patients. Frances Orsato and Peter Marotta did many of the blood and urine urea analyses.

\section{BIBLIOGRAPHY}

1. Goldblatt, H., Experimental hypertension induced by renal ischemia; Harvey Lecture. Bull. New York Acad. Med., 1938, 14, 523.

2. Blalock, A., and Levy, S. E., Studies on the etiology of renal hypertension. Ann. Surg., 1937, 106, 826.

3. Smith, H. W., Goldring, W., and Chasis, H., The measurement of the tubular excretory mass, effective renal blood flow and filtration rate in the normal human kidney. J. Clin. Invest., 1938, 17, 263.

4. Smith, H. W., Goldring, W., Chasis, H., and Ranges, H. A., Observations on the effective renal blood flow and functional excretory mass in man, with special reference to essential hypertension. Am. J. Physiol., 1938, 123, 189.

5. Corwin, J., and Herrick, W. W., Relation of hypertensive toxemia of pregnancy to chronic cardiovascular disease. J. A. M. A., 1927, 88, 457. 
6. Dill, L. V., and Erickson, C. C., Eclampsia-like syndrome occurring in pregnant dogs and rabbits following renal artery constriction. Proc. Soc. Exp. Biol. and Med., 1938, 39, 362.

7. Chesley, L. C., and Chesley, E. R., The diodrast clearance and renal blood flow in normal pregnant and non-pregnant women. Am. J. Physiol., 1939, 127, 731.

8. McCullagh, D. R., A new method for the determination of iodine. J. Biol. Chem., 1934, 107, 35.

9. Peters, J. P., and Van Slyke, D. D., Quantitative Clinical Chemistry. Vol. II. Methods. Williams and Wilkins Co., Baltimore, 1932, pp. 361-371, 602-604, 684.
10. Landis, E. M., Elsom, K. A., Bott, P. A., and Shiels, E. H., Simultaneous plasma clearances of creatinine and certain organic compounds of iodine in relation to human kidney function. J. Clin. Invest., 1936, 15, 397.

11. Stander, H. J., Williams Obstetrics. Appleton-Century, New York, 1936, 7th ed., p. 686.

12. Chesley, L. C., Renal function tests in the differentiation of Bright's disease from so-called specific toxemia of pregnancy. Surg. Gynec. and Obst., 1938, 67, 481.

13. Chesley, L. C., Certain laboratory findings and interpretations in eclampsia. Am. J. Obst. and Gynec., 1939, 38, 430. 